\title{
Gestão de Design e Planejamento Estratégico: Estudo de caso de uma loja do município de Belém do Pará
}

Management of Design and Strategic Planning: Case study of a store in the municipality of Belém do Pará

VIEIRA, Alessandra Farias; Especializando em MBA Gestão Empresarial; Faculdade Estratego.

Alessandrapgm39@gmail.com

CAVALCANTE, Rodrigo Augusto De Sousa; Mestrando em Design; Universidade Federal de Santa Catarina.

Rodrigo_171192@hotmail.com

MERINO, Eugenio Andrés Díaz; Doutor em Engenharia de Produção; Universidade Federal de Santa Catarina.

eugenio.merino@ufsc.br

\section{Resumo}

$\mathrm{O}$ artigo tem como objetivo desenvolver uma proposta de Plano de Marketing para a empresa AudioCar. A gestão de design junto ao planejamento estratégico permite que a empresa aperfeiçoe suas condições de administrar seus negócios. Esta união traz um raciocínio fundamental, para os novos modelos de gestão como base, os laços que se estreitam cada vez mais e a distância entre o modelo do negócio e cliente final, tem como finalidade a satisfação, não só do consumidor como da empresa também. A metodologia empregada foi o modelo Las Casas e o 4Ps do composto de Marketing. A primeira etapa da pesquisa foi de caráter exploratório. Na segunda o estudo de caso foi a análise de dados ocorridos do roteiro de entrevista informais. Constituiu verificar a geração de vantagem competitiva por intercessão do plano de marketing, visto que permite a informação do ambiente no qual a empresa está inserida recomendando ações estratégicas.

Palavras Chave: Gestão de Design; Planejamento estratégico; Plano de marketing.

\begin{abstract}
The article aims to develop a proposal for a Marketing Plan for the company AudioCar. Design management together with strategic planning allows the company to perfect its conditions of managing its business. This union brings a fundamental reasoning, for the new models of management as a base, the bonds that are increasingly narrowed and the distance between the business model and the end customer, has as purpose the satisfaction, not only of the consumer as of the company also. The methodology employed was the Las Casas model and the 4Ps of the Marketing compound. The first stage of the research was exploratory. In the second, the case study was the analysis of data from the informal interview script. It constituted to verify the generation of competitive advantage through intercession of the marketing plan, since it allows the information of the environment in which the company is inserted recommending strategic actions.
\end{abstract}


Keywords: Design Management; Strategic Planning; Marketing Plan.

\section{Introdução}

É indispensável planejar, para que se possa compreender onde se pretende caminhar, por esse motivo um plano corporativo pode ser responsável pelo sucesso ou pelo fracasso de uma empresa. De acordo com Cavalcanti (2014, p. 21) "A compreensão da postura estratégica das organizações parece mais clara quando a evolução é analisada sob uma perspectiva histórica, sendo possível detectar os acontecimentos mais determinantes das transformações ocorridas no ambiente produtivo.".

Armstrong e Baron (2005) falam que a gestão procura acrescentar valores a todos os recursos disponíveis, sendo que esse valor depende única e exclusivamente da competência e do compromisso das pessoas responsáveis pela gestão do negócio. De acordo com Carvalho (2009) sempre que exista a necessidade de tomar decisões para garantir o cumprimento de objetivos por meio da execução de atividades da forma mais eficiente possível, existe gestão.

Martins e Merino (2011, p. 93) "o processo de gestão resume-se no gerenciamento dos recursos da organização para alcançar objetivos estabelecidos." Neste caso, argumenta-se a gestão como uma função gerenciadora, pois advém principalmente da administração, do gerenciar para fazer de quem a implanta, como foco e estilo, na forma como se lida com a situação caótica buscando o controle. Enquanto o planejamento vem contribuir expressivamente para a formulação sistemática de objetivos e ações na qual se planeja alcançar mais, para que isso possa acontecer deve haver um planejamento de suas organizações, metas, estratégias de venda e na forma de como seus produtos vão chegar ao mercado consumidor.

Na maioria das micro e pequenas empresas pode-se verificar que não há um planejamento formal que oriente sua gerência. $O$ gestor tem ideia do caminho a ser percorrido e de onde almeja chegar, contudo, não há formalização em um plano. Com o aumento da concorrência e a nova realidade encarada por estas pequenas empresas, o uso do Plano de Marketing, asseado ao plano estratégico da empresa, ocorre a ser essencial forma de distinção e aquisição de vantagens competitivas. Segundo Longenecker et al (2007, p. 331) "os gestores das pequenas empresas, principalmente empresas novas e em crescimento, são limitados por condições que não constituem problemas aos executivos de uma grande empresa".

Ter uma orientação voltada para a estratégia de mercado, atendendo as necessidades e desejos dos clientes antes de seus concorrentes e de forma que seus produtos se tornem mais atrativos passou a ser a principal estratégia ser abraçada por uma empresa. Considerando esses interventores, surge a necessidade de se responder ao seguinte questionamento: como a gestão de design e planejamento estratégico pode beneficiar a empresa AudioCar Peças e Acessórios aprimorando sua competitividade?

O presente estudo teve como base, desenvolver uma proposta de plano de marketing para a empresa AudioCar da cidade de Belém-PA, por meio da ferramenta Swot onde será realizado um diagnostico para melhor compreender seu ambiente interno e externo, pois é o conhecimento da relação entre as variáveis do ambiente e a empresa, a utilização de tais dados será utilizado para a criação do planejamento estratégico são fundamentais para sucesso da organização.

Compreender o meio ambiente interno e externo da organização é essencial para que os objetivos possam ser alcançados (CARVALHO, 2009). Pelo meio da sua análise, o meio ambiente 
interno da organização reúne um conjunto de características da própria organização que possibilita identificar pontos fortes e pontos fracos e, perceber se a organização tem potencial competitivo em comparação com os seus concorrentes (SOUSA, 1990).

\section{Gestão de Design}

Para Mozota et al. (2011), a Gestão de Design acompanha as evoluções da gestão, que passou de um modelo taylorista para uma organização inteligente, flexível, que encoraja a tomada de decisões de risco, autonomia e a iniciativa, orientada ao usuário, o gerenciamento por projetos e a qualidade total, ajudando a mudança da cultura organizacional, tendo sua origem, segundo Mozota et al. (2011), nos anos 60, na Inglaterra, época em que a expressão significava a gestão da interface entre um escritório de design e seus clientes.

Soares (2007) define a Gestão de Design como a atividade macro das estratégias que designers estruturam para moldar um perfil da empresa com base nos produtos desenvolvidos e/ou na identidade visual que a representa. Para Padilha et al. (2010) a gestão de design está formulada como uma modalidade de pensamento, de ação, destinada a recuperar o protagonismo do design no marco da nova tipologia das mutações que se produzem nos fatores sociais, culturais, econômicos e tecnológicos.

Segundo Mozota (2003), é a falta de compreensão da extensão que ele abrange. Para essa satisfação, o designer necessita interagir com todos os setores da empresa envolvidos na produção, constituindo, assim, uma das ferramentas mais poderosas para a geração de benefício à indústria, tendo papel fundamental na inovação como forma de desenvolvimento de novas soluções e diferencial competitivo para as empresas.

Ainda Segundo a autora, a Gestão de Design possui um objetivo duplo: tornar gerentes e designers parceiros, a fim de ajudá-los a melhor gerenciar suas atividades; e definir os métodos de gestão para integrar o design na empresa. Para alcançar esse objetivo, precisa-se analisar mediante dois aspectos: a gestão dos processos de design e a relação do design com a gestão organizacional.

De acordo com Silva, Beltrame e Schmidt (2014, p. 300) apontam ainda como principais funções da gestão do design: "a definição dos objetivos e valores da empresa (missão); o desenvolvimento de uma estratégia baseada na missão; a execução e organização da estratégia; a coordenação e o controle do processo de produção; e o controle do resultado". Segundo Martins (2004, p. 10) define a importância da gestão do design como sendo: "processo e ferramenta estratégica, está na contribuição do design para a materialização de produtos e/ou de seus processos, incorporando os objetivos da empresa, tornando-se, desta forma, uma atividade necessária a organizações".

Silva, Beltrame e Schmidt (2014) afirmam que o enfoque da gestão de design consiste na qualidade devido às habilidades específicas dos designers: criatividade, iniciativa, atenção ao detalhe e atenção ao cliente. Deve ser, então, "uma ferramenta que integre as funções operacionais do design desenvolvido em todos os setores da empresa, visando atingir os objetivos traçados e propiciar a percepção de uma imagem positiva". (MARTINS, 2004, p. 102).

\subsection{Níveis da Gestão}

Mozota (2011) apresenta três níveis na gestão de design: operacional, tático e estratégico. 
O nível operacional consistiu no primeiro passo para integração do design, está relacionado com a percepção do projeto, com as atividades alcançadas durante o processo (MOZOTA, 2011; CPD, 1997). Esta forma de atuação é apreciada também como a prática do design, na qual se desenvolvem projetos precisos sob demanda (MERINO, 2010). Nível Tático ou Funcional diz respeito à criação de uma função de design na empresa para concretizar os acontecimentos. "Neste ponto, a empresa adquiriu experiência em design, bem como em uma sucessão de projetos de design" (MOZOTA, 2011, p. 257).

O nível do design estratégico consiste em gerir o reforço do design para o processo de formulação da estratégia, propondo estratégias que deem apoio às metas da organização, além de transmiti-las. (MOZOTA, 2011). A prática da gestão de design pode ser avaliada a partir do nível estrutural em que as decisões são adotadas: o nível operacional, o nível funcional (também chamado de tático) e o nível estratégico (MOZOTA, 2003).

Para, Magalhães (1997), Mallick (2000), Mozota (2003), Martins (2004), Kistmann (2006), as ações estão relacionadas à execução e desenvolvimento dos projetos há estrategicamente definido em:

- Nível operacional

Neste nível a gestão de design foca principalmente a gestão de projetos, desde a preparação do briefing, passando pela gestão de recursos humanos e financeiros, até a avaliação dos resultados obtidos pelo projeto. Além disso, a gestão de design necessita conduzir sua relação com a política e a estratégia de marketing da empresa e motivar confiança interna em design (MAGALHÃES, 1997).

A função operacional do design é fundamental para as organizações, constituindo uma base estrutural, comercial e produtiva para a empresa colocando os conhecimentos e as competências à prova, frente às ações da organização Martins (2004). Segundo Kistmann (2006), o design operacional é muito mais que executar o projeto, é manifestar serviços, elementos de comunicação externa e interna, observando as características do usuário estética e formal, componentes e possíveis alterações ergonômicas e análise de uso.

- Nível funcional ou tático

Segundo Kistmann (2006) o designer tem a responsabilidade de "concretizar os acontecimentos" de forma eficaz, eficiente, atendendo os desejos do consumidor.

Neste nível é importante compreender como inserir, criar e gerir um departamento de design, estabelecendo possíveis formas de interação com as outras áreas da empresa e como contribuir com o modelo de gestão da organização (MOZOTA, 2003). Isso compreende o planejamento, implantação, monitoramento, redução de riscos, minimizar incertezas, essas contribuições vêm para assegurar que essas atividades estejam de acordo com o plano estratégico da empresa.

- Nível estratégico

Mallick (2000) delibera o design estratégico a partir de um plano de ação para obter uma vantagem competitiva por meio do produto, do design do produto e de uma ascendência no atendimento às necessidades dos consumidores. Para Mozota (2003) a gestão do design no nível estratégico precisa constituir uma relação entre o design, a estratégia, a identidade e a cultura da 
empresa, com o desígnio de dar coerência ao trabalho do design e inseri-lo no processo de formulação da estratégia corporativa. O design precisa assumir então quatro papéis essenciais, que incluem:

- Enxergar a estratégia de negócio;

- Conhecer a competência central;

- Reunir informações de mercado;

- Inovar nos processos de gestão.

A partir desse contexto o profissional da área de design deve ter participação ativa na formulação da estratégia e na escolha dos processos, fazendo um esforço para apresentar o conhecimento de design para a composição desta visão, que tem como objetivo final demarcar a interação com o mercado. O tipo de estratégia de design adotado na organização está sujeito, em primeira instância, da importância oferecida à criatividade e à inovação.

\section{Planejamento Estratégico}

De acordo com Oliveira (1991), o planejamento estratégico é considerado uma ferramenta da área administrativa e da gestão empresarial, amplamente aproveitada pelas organizações e relacionada à estratégia empresarial, cujo, a sustentar o crescimento e da implementação de estratégias empresariais. Segundo Maximiano (2004, p. 385) planejamento estratégico "é o processo de desenvolver a estratégia - a relação pretendida da organização com o seu ambiente." O processo de planejamento estratégico compreende a tomada de decisões, que afetam a empresa por longo prazo, especialmente decisões sobre produtos e serviços que a organização pretende oferecer e os mercados e clientes que pretende atingir.

Para Las Casas (2007), o planejamento pode ocorrer de maneira informal, quando não há nenhuma metodologia específica implementada para sua realização, ou formal que para sua elaboração existe a necessidade do domínio de certas técnicas e conceitos que levam a melhores resultados.

O planejamento estratégico se inicia dentro da empresa quando a administração usa informações sobre o ambiente externo e os pontos fortes e fracos da mesma, para desenvolver uma visão de longo prazo a missão. A partir dessa análise torna-se possível a especificação de como se deve realizar essa missão, caracterizando o processo que envolve a criação de uma declaração de missão, objetivos organizacionais, estratégias organizacionais e um plano de portfólio organizacional que descreva as relações entre os vários produtos e linhas de produtos. Juntos esses elementos formam o plano estratégico da organização. (CHURCHILL E PETER, 2003).

Como parte integrante do planejamento estratégico a empresa necessita avaliar o seu ambiente e fazer uma análise completa de sua situação. Uma maneira de conduzir essa avaliação é por meio da análise SWOT (strengts, weaknesses, opportunities e threats), com a qual se avalia os pontos fortes e fracos, oportunidades e ameaças referentes à empresa.

A visão dessas análise integrada os componentes dos pontos fortes e fracos da empresa junto com as oportunidades e ameaças permitem identificar um conjunto de medidas estratégicas que possam vim apontar as características organizacionais e que ofereçam maior valor aos seus clientes e os aspectos que ela se encontra em desvantagem perante seus concorrentes, bem como também avaliar o impacto, positivo e/ou negativo, dos fatores referentes a oportunidades e 
ameaças sobre o desempenho atual da empresa.

Segundo Cavalcanti (2014, pág. 99) "Com amadurecimento da teoria sobre o planejamento estratégico verifica-se possíveis alterações conceituais que atenuam seu caráter prescritivo e que ampliam sua aplicação", nesse sentido de combinar técnica do planejamento com outros recursos que permitam uma melhor visão de contexto competitivo no qual a empresa está inserida. De outra parte, os objetivos, metas e indicadores, eleitos no planejamento estratégico, podem funcionar com parâmetros de controle dedicados a avaliação do processo de prática da proposta.

\subsection{Plano de Marketing}

O ponto chave para o planejamento de uma empresa está ligado ao plano de marketing, pois este identifica as oportunidades de negócios mais propícias para a empresa e vem definir como penetrar, conquistar e manter posições em mercados identificados. De acordo com Las Casas (2007, p.18) “O plano de marketing estabelece objetivos, metas e estratégias do composto de marketing em sintonia com o plano estratégico geral da empresa. É toda a relação produto/mercado que, em conjunto com outros planos táticos, forma o plano estratégico.".

O plano é ligado por diversos subplanos, chamados planos operacionais (plano de vendas, propaganda, merchandising) e cada um tem seu papel específico para alcançar os objetivos da empresa. Segundo Kotler e Keller (2006, p.58) “Um plano de marketing é um documento escrito que resume o que o profissional de marketing sabe sobre o mercado e que indica como a empresa planeja alcançar seus objetivos".

De acordo com Las Casas (2007, p.37) “As principais informações de um plano de marketing são aquelas que se referem ao mercado, aos consumidores, aos programas de marketing e à alocação dos investimentos necessários". Dessa forma o plano de marketing está espontaneamente unido aos objetivos de longo prazo da empresa e não necessita ser estruturado sem apreciar as demais partes do mesmo, além disso, os planos operacionais devem estipular os detalhes das atividades que foram esboçadas na estratégia de marketing.

Muitos autores afirmam em suas publicações, Vyakarnam e Leprard (1996); Churchill e Peter (2000); Las Casas (2007) que a elaboração do plano de marketing para administradores e donos de pequenas empresas pode parecer demasiadamente um cerimônia e demorado, entretanto esses profissionais tendem a passar mais tempo ajustando problemas do que apresentaria uma solução na criação de um novo plano de marketing. No caso de uma pequena empresa o plano de marketing pode abranger as atividades de marketing da empresa como um todo, diferentemente de uma grande empresa que geralmente é especifico para um determinado produto ou linha de produtos.

Portanto, é importante que exista dentro da empresa um sistema de gestão e design, para que as diretrizes voltadas ao desenvolvimento do plano de marketing sejam coerentes no início e os objetivos alcançados no final. Logo, se faz necessária à integração de diferentes domínios profissionais que possam vim contribuir, tanto para o desenvolvimento quanto para sua aplicação.

\section{Metodologia}

A natureza da pesquisa caracteriza-se por ser aplicada, já que foi criada a partir da necessidade de resolver problemas concretos, como a falta de um planejamento estratégico para a empresa (VERGARA, 2009). Além disso, Silva e Menezes (2001, p. 21) definem a pesquisa 
aplicada como: "objetiva, pois gera conhecimentos para aplicação prática dirigida à solução de problemas específicos. Envolve verdades e interesses locais".

Esta análise trata-se de uma pesquisa exploratória de caráter qualitativo com o objetivo de compor a proposta de um plano de marketing para empresa AudioCar, apoiado com a pesquisa de campo por meio de visitas para analisar o ambiente mercadológico do segmento em que a empresa se encontra de modo a se obter o informação das principais características concorrenciais, isto é, como são comercializados os produtos, quais os diferenciais, preços, estratégias de distribuição, vendas e comunicação e outras informações que sejam relevantes.

As metodologias utilizadas basearam-se na condução de uma pesquisa exploratória que de acordo com Malhotra (2011. P. 57), busca "explorar ou examinar um problema ou situação para se obter conhecimento e compreensão". Visando proporcionar o máximo de familiaridade com o problema. Segundo Vergara (2009, p. 47) abordar ainda de uma pesquisa bibliográfica, pois "é um estudo sistematizado desenvolvido com base em material publicado".

No caso do estudo em questão, as características que se referem estão voltadas para a construção de um plano de marketing. Já quanto aos métodos técnicos, se deliberou como pesquisa de campo que é utilizada com o propósito de alcançar informações ou conhecimentos acerca de um problema, para o qual se procura uma resposta, ou de uma hipótese que se queira comprovar. Segundo Yin (2001, p. 35), "estudo de caso, como outras estratégias de pesquisa, representa uma maneira de se investigar um tópico empírico seguindo-se um conjunto de procedimentos pré - especificados". Optou-se por realizar uma pesquisa qualitativa a partir da utilização do método "estudo de caso", escolhido em função da possibilidade de investigação profunda e exaustiva do fenômeno a ser estudado e a compreensão mais próxima da realidade social.

Inicialmente procedeu-se a análise dos dados secundários internos (gerados dentro da empresa) quanto externos (gerados por fontes de fora da empresa) de modo a diagnosticar o ambiente mercadológico vivenciado pela empresa AudioCar. Esses dados foram coletados por meio de questionários com perguntas para os colaboradores, gerente, proprietário, concorrentes e clientes, tornando-se assim possível a identificação da situação do segmento foco de estudo, a partir de informações sobre a concorrência, tendências e evolução do mercado.

A entrevista não padronizada teve como amostra o gerente e o proprietário da AudioCar, por serem eles os principais responsáveis pelas estratégias da empresa. Respectivamente, realizou-se uma pesquisa de campo do tipo cliente oculto, em três concorrentes selecionados aleatoriamente, permitindo uma análise comparativa com o objetivo de propor ações de melhoria para o negócio da empresa.

Para as pequenas empresas faz necessária a utilização de um plano mais objetivo possível por não haver um suporte regular, por esse motivo expõe uma metodologia mais simples podendo transportar como base para o planejamento da micro e pequena empresa ou então como estreito inicial para o planejamento dos empresários de grandes empresas. De acordo com Las Casas (2007, p.38), essa metodologia é denominada como "roteiro simplificado para um plano de marketing" e conclui:

1. Análise ambiental: oportunidades e ameaças, pontos fortes e pontos fracos.

2. Objetivos: qualitativos e quantitativos. 
3. Estratégias de marketing: púbico alvo, posicionamento, estratégia do composto de marketing (preço, praça, distribuição e promoção).

4. Plano de ação.

5. Projeção de vendas e lucros.

De modo a estruturar o plano de marketing para a empresa apresenta-se a análise concorrencial, acima citada, por meio de um quadro comparativo entre a empresa e a concorrência, da mesma forma descreve-se um quadro dos principais pontos fortes e fracos, ameaças e oportunidades da empresa, evidenciadas a partir da análise de mercado, concorrência e atributos internos da empresa, bem como as estratégias de marketing e o plano de ação que possibilite atingir o objetivo de marketing proposto.

\section{Empresa AudioCar}

O estudo de caso foi realizado no município de Belém - Pará, a empresa chama-se AudioCar, localizada no bairro do Umarizal, no decorrer de sua experiência no mercado peças e acessórios para carro em Belém há 12 anos, têm proporcionado um considerável crescimento frente a participação no mercado verificado especialmente um significativo aumento no percentual das vendas e prestígio de sua empresa, posicionando-se como empresa que oferece produtos e serviços de qualidade. Atualmente constitui-se como micro empresa (em razão de seu faturamento e número de funcionários) de âmbito familiar e conta com cinco funcionários, sendo um gerente com função administrativa e compras, um proprietário com função de compra e venda, três funcionários com a parte operacional e de assistência.

Recentemente, a empresa apresenta-se focada no aumento da participação de mercado, fato decorrente da utilização de serviços e produtos de qualidade, bom atendimento e por meio de investimentos que proporcionam maior qualidade de produtos e atendimento ao público, como manutenção e reparos de veículos caso seja necessário.

A empresa não possui missão, visão e valores, os objetivos e metas estabelecidas são de maneira informal, onde trabalham conforme a orientação que o mercado aconselha. Episódio esse que comprova a imprescindível necessidade de um planejamento para a empresa. Quanto às ações de promoção e divulgação não há muitos critérios, sendo necessário um orçamento que atenda as necessidades da empresa.

\subsection{Análises das Entrevistas}

Constatou-se na entrevista com o proprietário considera o marketing importante para os negócios da empresa, apesar de não fazer uso dele de maneira planejada, acredita que a divulgação e reforço da empresa são fundamentais para aumentar a participação no mercado, manter-se competitivo e sustentar as margens de vendas. Utilizam uma página na rede social, layout na frente da loja, adesivos para colocar nos carros dos clientes e final de ano como brinde entregam chaveiros aos seus clientes. Acreditam que o bom atendimento e a qualidade dos produtos e serviços ofertados são essenciais para a fidelização e/ou retenção dos clientes e que o comprometimento dos funcionários a fazer aquilo que consideram saber fazer são os atributos que os levam a busca de melhorias contínuas para seus clientes, produtos e empresa.

Os concorrentes da AudioCar são as lojas de peças e acessórios que ficam localizadas aos arredores da empresa, seu público alvo não é bem segmentado devido à oferta de vários tipos de produtos diferentes dos que a empresa em estudo oferta, e possuem os mais variados preços e 
marcas. No entanto, pode-se dizer que por trabalhem com produtos em sua maioria de porte médio, são a classe $A$ até a $C$ que procuram a aquisição desses produtos, o nicho de clientes se diferenciam um pouco frente aos concorrentes.

Por meio da entrevista, compreender que os pontos fortes da empresa são: excelente qualidade dos produtos, comprometimento dos funcionários, bom atendimento aos clientes, fornecedores de boa reputação, localização estratégica, e a negociação do preço com o cliente. Quanto às fraquezas, consistir em: poucos funcionários para atendimento ao público, estoque reduzido em determinadas épocas e propaganda pouco consistente e a falta de estacionamento, e de uma sala de espera para os clientes. Eles enxergam como chance a expansão do segmento abrindo uma filial em outro local na cidade, aumentando o poder de compra da classe média e a facilidade de crédito, destacando a taxa de juros, pois compra o produto a vista podendo assim ter o poder de negociação maior com o cliente, atuando com isso na oportunidade para o aumento das vendas, ora como ameaça á elas, da mesma forma que o crescimento do ramo ocasiona a entrada de muitos adversários, além da dificuldade de acesso á mão de obra especializada.

Evidenciou-se que o administrador da empresa, apesar de descrever que não existe muito tempo para as questões de planejamento, procurar seguir conforme o direcionamento do mercado de maneira reativa busca sempre oportunidade de reestrutura às mudanças, demonstrando ter a empresa ações de atendimento as necessidades e desejos dos clientes, que a leva a se manter competitiva em relação ás outras empresas do mesmo setor.

Com relação ao mix de marketing as entrevistas permitiram entender que quanto ao produto, a qualidade atribuída às revisões e manutenção é o principal atributo deste, pode ser adaptado de acordo com a preferência do cliente, proporcionam garantia, são produtos de variadas marcas e modelos e de preço variados. Quanto à promoção a empresa utiliza poucos meios para informar e comunicar seus clientes dos benefícios e vantagens de seu produto. Utiliza apenas: a página da loja em uma rede social e o boca a boca. Em inclusão ao futuro e crescimento da empresa, o proprietário almeja conseguir outros nichos de mercado por meio da diversificação de serviços como, por exemplo, a abertura de uma filial, para que possa atender clientes da classe D assim criando uma maneira de aumentar seu percentual de lucro e promover a expansão da empresa AudioCar.

\section{Plano de Marketing Proposto para Empresa}

O plano apresentado recomenda-se um plano operacional alinhado a estratégia empresarial que consinta ao proprietário e colaboradores conhecerem o diagnóstico atual da empresa e o que pode ser feito para aperfeiçoar sua competitividade, operando também como direcionador das atividades a partir do planejamento das ações e estratégias a serem conquistadas.

\subsection{Diagnóstico de mercado}

De acordo com Castanho Neto (2013) editor da revista Automotiva apresenta dados de um estudo de Roland Berger o Strategy Consultants que expõe o seguinte, "o mercado brasileiro de som e acessórios representa $10 \%$ do mercado total de autopeças e componentes automotivos, movimentando um total de 2 bilhões de reais anualmente, contra 20 bilhões de reais do mercado total.". Em Belém no estado do Pará pode se observar que a Avenida Domingos Marreiros se caracteriza como um mercado extremamente competitivo, visto que se percebe o constante 
surgimento de novas empresas desse setor e o crescimento de outras já existentes, emergindo assim a necessidade por parte das empresas de fazerem uso do marketing para impulsionar as vendas, atrair e reter clientes e aumentar sua participação no mercado.

Segundo Castanho Neto (2013), o mercado deve crescer fortemente nos próximos anos, se expandido a taxas bem superiores às do mercado automotivo em geral. Apesar do acirramento da concorrência a empresa vem aumentando sua participação no mercado por meio do aumento das vendas e reforçando sua marca por meio da propaganda boca a boca, com isso percebe-se a necessidade de trabalhar com mais criteriosidade o marketing da empresa de maneira a melhorar sua competitividade e se diferenciar de suas concorrentes.

\subsection{Diagnóstico da concorrência}

No meio de diversas lojas da Avenida Domingos Marreiros onde se localiza a empresa e da Avenida Antônio Barreto, onde se situa os concorrentes, foram escolhidas três concorrentes aleatoriamente para realização de uma pesquisa do tipo cliente oculta. A pesquisa foi realizada no mês de Janeiro de 2018 e buscou-se fazer uma comparação entre atributos previamente estabelecidos da AudioCar e suas concorrentes.

\subsection{Diagnóstico do SWOT}

Por meio da análise do mercado, da concorrência e do ambiente interno da empresa apresentam-se os pontos fortes e fracos e as oportunidades e ameaças conforme o quadro 1 e no quadro 2 meta e objetivos da empresa para 2018.

Quadro 1 - Resultado do SWOT

\begin{tabular}{|c|c|}
\hline Pontos fortes & Pontos fracos \\
\hline $\begin{array}{l}\text { - Preço competitivo; } \\
\text { - Oferece produtos de boa qualidade; } \\
\text { - Dirigentes da empresa reconhecem que o } \\
\text { uso do marketing na empresa precisa } \\
\text { melhorar; } \\
\text { - Pratica políticas de análise da concorrência; } \\
\text { estão atentos as mudanças do mercado; } \\
\text { - Comprometimento dos funcionários; } \\
\text { - Considera o atendimento ao cliente uma } \\
\text { prioridade; } \\
\text { - Fornecedores de boa reputação. }\end{array}$ & $\begin{array}{l}\text { - Não têm objetivos e metas de vendas estabelecidas; } \\
\text { - Quadro reduzido de funcionários nas épocas de altas } \\
\text { de vendas; } \\
\text { - Falta treinamento para a equipe; } \\
\text { - Não anunciam na mídia e redes sociais; } \\
\text { - Proprietário considera o marketing um custo apenas } \\
\text { empresas de porte maior podem praticar e acreditam } \\
\text { precisar contratar um profissional } \\
\text { - Não tem planejamento: } \\
\text { competitivas; } \\
\text { - Não usa consultores e assessorias externas; } \\
\text { - Não tem um posicionamento consistente. }\end{array}$ \\
\hline Oportunidades & Ameaças \\
\hline $\begin{array}{l}\text { - Facilidade de crédito: taxa de juros baixos, } \\
\text { parcelamento no cartão, negociação de } \\
\text { preço; } \\
\text { - Maior interesse da população pelo carro } \\
\text { próprio; } \\
\text { - Crescimento do setor no estado. }\end{array}$ & $\begin{array}{l}\text { - Carência de mão de obra especializada; } \\
\text { - Poder de barganha das concorrentes que também } \\
\text { ofertam produtos com valor menor; } \\
\text { - Aumento da concorrência: necessidade de } \\
\text { diferenciação, investimentos em pessoal, comunicação, } \\
\text { imagem corporativa e tecnologia. }\end{array}$ \\
\hline
\end{tabular}

Fonte: Dados da pesquisa (2018) 


\subsection{Metas e Oportunidades}

Quadro 2 - projeção para 2018

\begin{tabular}{|l|l|}
\hline \multicolumn{1}{|c|}{ Objetivos } & \multicolumn{1}{|c|}{ Metas } \\
\hline - Ser referência entre as empresas do segmento; & - Estabelecer cotas de vendas mensais de 30\% do \\
- Fornecer produtos da melhor qualidade e o & $\begin{array}{l}\text { Estoque; } \\
\text { melhor atendimento; } \\
\text { - Garantir a satisfação do cliente; }\end{array}$ \\
- Ter uma campanha de divulgação adequada; & primeiros meses; \\
- Melhorar a competitividade da empresa no & - Assistência individual durante a venda; \\
segmento; &
\end{tabular}

Fonte: Autores (2018)

\subsection{Estratégia de Marketing e Plano de Ação}

Apresentam-se nesta etapa do plano de marketing as estratégias e ações quanto ao mix de marketing para atingir os objetivos propostos. Para dar coerência e ordem ao plano são apresentados respectivamente nos quadros 3 a 6 especificando as atribuições e prazos relacionado ao 4 Ps.

Quadro 3 - Produtos e Serviços

\begin{tabular}{|c|c|c|}
\hline Estratégias & Ação & Período \\
\hline $\begin{array}{l}\text { Qualidade dos produtos } \\
\text { Ofertados. }\end{array}$ & $\begin{array}{l}\text { Colocar um funcionário } \\
\text { específico para tratar de } \\
\text { assuntos relativos à } \\
\text { manutenção e reparos dos } \\
\text { serviços prestados a sustentar a } \\
\text { aumento da garantia como ação } \\
\text { promocional. }\end{array}$ & Diariamente \\
\hline $\begin{array}{l}\text { Atendimento de excelência ao } \\
\text { cliente. }\end{array}$ & $\begin{array}{l}\text { Funcionários capacitados com } \\
\text { cursos de técnicas de vendas, } \\
\text { argumentos negociais e } \\
\text { conhecedores dos principais } \\
\text { atributos de cada produto; Criar } \\
\text { um arquivo de pessoas } \\
\text { qualificadas a vagas temporárias } \\
\text { no período de altas de vendas. }\end{array}$ & $\begin{array}{l}\text { Até o primeiro semestre de } \\
2019\end{array}$ \\
\hline
\end{tabular}

Fonte: Autores (2018) 
Quadro 4 - Preço

\begin{tabular}{|l|l|l|}
\hline \multicolumn{1}{|c|}{ Estratégias } & \multicolumn{1}{|c|}{ Ação } & \multicolumn{1}{c|}{ Período } \\
\hline $\begin{array}{l}\text { Diferenciar o preço em datas } \\
\text { esporádicas. }\end{array}$ & $\begin{array}{l}\text { Verificar no estoque peças e } \\
\text { acessórios que foram obtidos a } \\
\text { um custo menor e/ou margem } \\
\text { de lucro maior e ofertar a preço } \\
\text { abaixo da concorrência. }\end{array}$ & A cada três meses. \\
\hline
\end{tabular}

Fonte: Autores (2018)

Quadro 5 - Praça

\begin{tabular}{|l|l|l|}
\hline \multicolumn{1}{|c|}{ Estratégias } & \multicolumn{1}{|c|}{ Ação } & \multicolumn{1}{c|}{ Período } \\
\hline $\begin{array}{l}\text { Ofertar maior variedade de } \\
\text { produtos. }\end{array}$ & $\begin{array}{l}\text { Buscar parcerias com } \\
\text { fornecedores e gerir os estoques }\end{array}$ & Até janeiro de 2019. \\
\hline
\end{tabular}

Fonte: Autores (2018)

Quadro 6 - Promoção

\begin{tabular}{|c|c|c|}
\hline Estratégias & Ação & Período \\
\hline \multirow[t]{3}{*}{$\begin{array}{l}\text { Melhorar a comunicação da } \\
\text { empresa. }\end{array}$} & $\begin{array}{l}\text { Criar uma ação de divulgação } \\
\text { por meio de placas e anúncios } \\
\text { que venham mostrar as ofertas } \\
\text { e facilidades de compra da loja } \\
\text { (vendas no cartão, cobrir o } \\
\text { preço da concorrência frente a } \\
\text { comprovação do valor). }\end{array}$ & Uma vez por mês. \\
\hline & $\begin{array}{l}\text { Disponibilização de folders em } \\
\text { empresas parceiras } \\
\text { frequentadas pelo público alvo } \\
\text { (locadora e concessionarias). }\end{array}$ & Diariamente. \\
\hline & Utilização das redes sociais. & Diariamente. \\
\hline \multirow[t]{2}{*}{$\begin{array}{l}\text { Estreitar o relacionamento com } \\
\text { os clientes. }\end{array}$} & $\begin{array}{l}\text { Manter uma base de dados de } \\
\text { clientes atualizadas; Enviar e- } \\
\text { mail com novidades e } \\
\text { promoção; oferta de descontos } \\
\text { e brindes especiais na data de } \\
\text { aniversário e para clientes que } \\
\text { voltam a fazer serviços na } \\
\text { empresa. }\end{array}$ & Diariamente \\
\hline & $\begin{array}{l}\text { Aumentar o prazo de garantia } \\
\text { para } \\
\text { Determinados acessórios. }\end{array}$ & Esporadicamente. \\
\hline
\end{tabular}

Fonte: Autores (2018) 


\section{Considerações Finais}

Este artigo exibiu como motivo principal a inexistência de um plano de marketing na empresa AudioCar e o panorama atual das pequenas empresas do mesmo ramo. As quais têm proporcionado grandes dificuldades para se sustentar em seus relativos segmentos dada à fragilidade que o ambiente competitivo revelar-se a cada dia se torna extremamente hostil, no qual muitas vezes se faz indispensável à pequena empresa concorrer com os grandes, que possui condições estruturais bem elevados.

Baseando-se nas informações coletadas a partir da ferramenta a cima pôde-se concluir que a gestão de design é cada vez mais entendida de forma a incentivar o intercâmbio de conhecimentos em diversas áreas. Portanto, por meio de estratégias bem apresentadas, utilização de metodologia, técnicas e ferramentas de design, esta área é entendida como um diferencial estratégico, partindo além do estilo e adaptando vantagem competitiva.

As empresas de pequeno porte consistem em estar bem acentuadas no contexto socioeconômico brasileiro em suas atividades comerciais, sendo identificada como fator de ascensão social, cujas empresas, são base para equilíbrio, política e força propulsora do desenvolvimento do mercado, apresentada a este a mesma habilidade de motivar empregos e congregar novos procedimentos.

O plano exposto permite ao proprietário da empresa melhores condições de gerir seu negócio a partir do momento que se pode levar a informação da empresa um diagnóstico do ambiente no qual ela está implantada, a fim de sugerir ações estratégicas que tendem contornar as ameaças em oportunidades e os pontos fracos em pontos fortes, por meio de técnicas contidas no modelo de plano de marketing que ampare nas decisões tomadas pelo administrador, que busque atrair, cultivar e fidelizar seu público alvo, acrescendo também sua lucratividade e assim tudo que for planejado consiga dar resultados.

O plano de ação aconselha que algumas atividades ao qual venha ser adotada pela empresa AudioCar. Ficou recomendado que pudesse ser investido em qualificação para os funcionários, que seja concretizada uma melhor divulgação da loja, que seja constituída uma parceria entre seus fornecedores, podendo assim conseguir um melhor artifício de preço, tirar proveito da internet como meio de divulgação, por meio de sites e redes sociais, que irão proporcionar a empresa a atuar em um mercado virtual, no qual cresce a cada dia.

A pesquisa demonstrou ser possível uma vantagem competitiva por intercessão do plano de marketing, pois embora as dificuldades para conseguir se alimentar e crescer no mercado, uma dos principais benefícios da empresa ao ser formulada no plano e contribuir como ferramenta seria um diagnostico que permita reconhecer seu ambiente interno intensamente, ter a informação mais breve de seus adversários e seu ambiente mercadológico, na qual faz detectar mais rapidamente suas necessidades e transformá-las em oportunidades de negócios, desmistificando o conceito que os planos são aplicáveis somente em grandes empresas e ressaltando que a adaptação a sua realidade de trabalho se torna um bom trunfo.

Cada etapa dessa pesquisa foi importante para compreender a relação entre a gestão de design e o planejamento estratégico, como eles podem contribuir, valorizar e/ou alavancar um empreendimento. $O$ planejamento estratégico vem com o intuito de orientar a empresa para que 
a mesma possa alcançar seus objetivos, o processo de gestão de design vem configurado em uma estratégia de transformar os desejos criando um possível caminho ao que provavelmente se poderá seguir, pois se sabe que falta uma visão sistêmica e de mercado por parte dos empresários.

Infelizmente não foi possível aplicar e estudar a fase de implementação do plano estratégico desta pesquisa e assistir quais seriam as evoluções, pontos acertados e errados e a reestruturação de um novo plano estratégico, mas almeja aplicação para primeiro semestre do ano de 2019.

\section{Referências}

ARMSTRONG, M., \& BARON, A. Managing performance - performance managing in action. London: Chartered Institute of Personnel and Development, CIPD House. 2005.

CARVALHO, J. Gestão de empresas - princípios fundamentais. Lisboa: Edições Sílabo. 2009.

CASTANHO NETO, Amadeu. Tendências no mercado brasileiro de acessórios automotivos. 2013. Disponível em: <http://revistaautomotivo.com.br/auto/tendencias-no-mercado-brasileiro-deacessorios-automotivos/>. Acesso em: 23 fev. 2018.

CAVALCANTI, Francisco Antônio. Planejamento estratégico participativo: concepção, implementação e controle de estratégias. São Paulo 2014.

CENTRO PORTUGUÊS DE DESIGN. Manual de gestão do design. Porto, 1997.

CHURCHILL JR, G.A.; PETER, J.P. Marketing: Criando valor para os clientes. São Paulo: Saraiva 2003. KOTLER, Philip; KELLER, Kevin Lane. Administração de marketing. 12. ed. São Paulo: Pearson Prentice Hall, 2006.

LAS CASAS, A.L. Plano de marketing para micro e pequena empresa. 5.ed. São Paulo: Atlas, 2007

LONGENECKER, J.G. et al. Administração de pequenas empresas. Trad. Oxbridge Centro de Idiomas. Revisão de Álvaro Mello, Carlos Tasso Lira de Aquino e Raul Ribas. São Paulo: Thomson, 2007.

KISTMANN, V. B. Apresentação da disciplina de fundamentos de sistema de produção e utilização. Curitiba, mestrado em design do programa de pós-graduação em design (ppgdesign), Universidade Federal do Paraná, 2006.

MAGALHÃES, Cláudio Freitas. Design estratégico: integração e ação do design industrial dentro das empresas. Rio de Janeiro. SENAI/DN, SENAI CETIQ, CNPq, IBICT, TIB. 1997.

MALHOTRA, N.K. Pesquisa de Marketing: foco na decisão. Tradução Opportunity Translations. São Paulo: Pearson Prentice Hall, 2011.

MAXIMIANO, Antônio César Amaru. Teoria geral da administração: da revolução urbana à revolução digital. 4 ed. São Paulo: Atlas, 2004

MALLICK, D. N. The design strategy framework. Boston: DMI- Design Management Institute, Review Article, v. 11, n. 3, summer, 2000.

MARTINS, R. F. D. F. A Gestão de Design como uma Estratégia Organizacional: um Modelo de Integração do Design em Organizações. 2004. Tese (Doutorado em Engenharia de Produção) - 
PPGEP

UFSC

Florianópolices.

Disponível

em:

<https://repositorio.ufsc.br/bitstream/handle/123456789/87100/208973.pdf?sequence=1\&isAllo wed=y>. Acesso em: 10 jan. 2018.

MARTINS, Rosane Fonseca de Freitas, MERINO, Eugenio A. D. Gestão de Design como Estratégia Organizacional. 2a. ed. Londrina: EDUEL, 2011.

MERINO, Giselle Schmidt Alves Diaz. A contribuição da gestão de design em grupos produtivos de pequeno porte no setor da maricultura: o caso AMPROSUL. 2010. 184f. Dissertação (mestrado) Universidade Federal de Santa Catarina, Programa de Pós-Graduação em Design e Expressão Gráfica.

MOZOTA, B. B. Using design to build brand value and corporate innovation. New York: Allworth Press, 2003.

MOZOTA, Brigitte Borja de; KLÖPSCH, Cássia; COSTA, Felipe C. Xavier Da. Gestão de Design: usando o design para construir valor de marca e inovação corporativa. Porto Alegre: Bookman, 2011. $344 \mathrm{p}$.

OLIVEIRA, D.P.R. Estratégia Empresarial. São Paulo, Atlas. 1991.

PADILHA, A. C. M.; CARVALHO, F. F.;MATTOS, P.; GOLLO, S. S. A gestão de design na concepção de novos produtos: uma ferramenta de integração do processo de gestão e inovação. Rev. adm. UFSM. Santa Maria, v. 3, n. 3, p. 346-360, set/dez. 2010. Disponível em: < https://periodicos.ufsm.br/reaufsm/article/download/2503/1531>. Acesso em: 05 jan. 2018.

SILVA, J. P. M. D.; BELTRAME, T. F.; SCHMIDT, A. D. A gestão do design como diferencial de qualidade nas indústrias moveleiras do alto uruguai gaucho. Rev. Adm. UFSM, Santa Maria, v. 7, número 2, $\quad$ p. $296-314, \quad 2014 . \quad$ Disponível em: https://periodicos.ufsm.br/reaufsm/article/download/7144/pdf >. Acesso em: 12 jan. 2018.

SILVA, E. L. D.; MENEZES, E. M. Metodologia da pesquisa e elaboração de dissertação. 138 p. 4. ed. rev. atual. - Florianópolis: UFSC, 2005.

SOARES, V. F. UFRJ. Escola de Belas Artes. Curso de Desenho Industrial. Disciplina Projeto de Produto. Rio de janeiro. 2007. Disponível em:< http://www.eba.ufrj.br/aula/gp/>. Acesso em: 08 jan. 2018.

SOUSA, A. Introdução à gestão - uma abordagem sistémica. Lisboa: Verbo, Editorial. 1990.

VERGARA, S.C. Projetos e Relatórios de Pesquisa em Administração. 11 ed. São Paulo: Atlas, 2009.

VYAKARNAM, S.; LEPPARD, J.W. Como montar um plano de ação de marketing: guia prático. 2 ed. Tradução José Carlos Barbosa dos Santos. São Paulo: Makron Books Brasil, 1996.

YIN, Robert k. Estudo de caso: planejamento e métodos. 2a Ed. Porto Alegre: Bookman, 2001.

Agradecimento a CAPES, pela concessão de bolsa de estudo a Rodrigo Cavalcante e Empresa AudioCar pelo apoio durante o período da pesquisa. 